\title{
Distribución mundial de la población con discapacidades en relación con los patrones geográficos del desarrollo humano*
}

\author{
Ernesto Cutillas Orgilés \\ Universitat d'Alacant. Departament de Geografia Humana \\ ernesto.cutillas@ua.es
}

\section{Resumen}

Distintos enfoques científicos han estudiado los espacios de vida en donde existen factores ambientales y sociales que dificultan el acceso y la participación de las personas con discapacidades. En dicho sentido, la distribución de esta población mantiene cierto paralelismo con el reparto de determinados indicadores sociales y de desarrollo a nivel mundial. En el presente trabajo, se consideran una serie de indicadores procedentes del Informe mundial sobre la discapacidad para identificar a aquellos que contribuyen mejor a explicar la distribución geográfica de los años vividos con discapacidad a escala global. Pese a las limitaciones de las fuentes de información utilizadas y a la dificultad de establecer relaciones causaefecto, los resultados obtenidos describen que la prevalencia de la discapacidad no siempre se vincula con el envejecimiento demográfico en los países en desarrollo, mientras que la población con elevados años vividos con discapacidad se incrementa en aquellas regiones donde los niveles de desarrollo humano y el índice de desigualdad de género reflejan notables contrastes sociales.

Palabras clave: discapacidad; desarrollo; países; años vividos con discapacidad

Resum. Distribució mundial de la població amb discapacitats en relació amb els patrons geogràfics del desenvolupament humà

Hi ha hagut diferents enfocaments científics que han estudiat els espais de vida on trobem factors ambientals i socials que dificulten l'accés i la participació de les persones amb discapacitats. En aquest sentit, la distribució de la població amb discapacitats manté cert paral-lelisme amb el repartiment de determinats indicadors socials i de desenvolupament a nivell mundial. En el present treball, s'hi consideren una sèrie d'indicadors procedents de l'Informe mundial sobre la discapacitat per identificar aquells que contribueixen millor a explicar la distribució geogràfica dels anys viscuts amb discapacitat a escala global. Malgrat les limitacions de les fonts d'informació utilitzades i la dificultat d'establir relacions causa-efecte, els resultats obtinguts descriuen que la prevalença de la discapacitat no sempre es vincula amb l'envelliment demo-

* Este trabajo se ha realizado en el marco del proyecto de investigación emergente GRE13-06, financiado por el programa propio del Vicerrectorado de Investigación de la Universidad de Alicante. 
gràfic en els països en desenvolupament, mentre que la població amb molts anys viscuts amb discapacitat augmenta en aquelles regions on els nivells de desenvolupament humà i l'índex de desigualtat de gènere reflecteixen contrastos socials notables.

Paraules clau: discapacitat; desenvolupament; països; anys viscuts amb discapacitat

Résumé. Répartition mondiale de la population handicapée en relation avec les tendances géographiques du développement humain

Différentes approches scientifiques ont étudié les espaces de vie dans lesquels des facteurs environnementaux et sociaux entravent l'accès et la participation des personnes handicapées ; à cet égard, la population handicapée présente un certain parallèle avec la distribution de divers indicateurs sociaux et de développement à travers le monde. Dans cet article, nous considérons un ensemble d'indicateurs du Rapport mondial sur le handicap pour identifier ceux qui contribuent à expliquer la répartition géographique des années vécues avec un handicap. Malgré les limitations des sources d'information utilisées et la difficulté à établir des relations de cause à effet, les résultats montrent que la prévalence du handicap n'est pas toujours associée au vieillissement démographique dans les pays en développement, alors que la population qui présente de nombreuses années vécues avec un handicap a augmenté dans les régions où les niveaux de développement humain et l'indice d'inégalités de genre montrent d'importants contrastes sociaux.

Mots-clés: handicap; développement; pays; années vécues avec un handicap

Abstract. Global distribution of the population with disabilities in relation to geographic patterns of human development

Various scientific approaches have studied the living spaces where existing environmental and social factors hinder the access and participation of people with disabilities. In this regard, the distribution of the population with disabilities broadly parallels the distribution of other social indicators and development worldwide. In this paper, we consider a set of indicators from the World report on disability to identify those that better explain the geographical distribution of years lived with disability (YLD) on a global scale. Despite the limitations of the data sources and the difficulty of establishing cause-effect relationships, the results reveal that the prevalence of disability is not always linked to the aging population in developing countries, while the population with a high YLD increases in regions where levels of human development and the gender inequality index reflect significant social disparities.

Keywords: disability; development; countries; years lived with disability

\section{Sumario}

1. Introducción. Los modelos de discapacidad y su plasmación territorial

2. La definición de la discapacidad: factores, conceptualización y disparidades en las fuentes de información

3. Los años vividos con discapacidad y su relación con indicadores de desarrollo humano
4. Planteamiento metodológico y resultados

5. Desarrollo y discapacidad: pautas en la distribución geográfica de la esperanza de vida al nacer e índice de desigualdad de género
6. Conclusiones
Referencias bibliográficas 


\section{Introducción. Los modelos de discapacidad y su plasmación territorial}

Los procesos socioterritoriales por los que se producen (y se reproducen) desventajas son una constante en cualquier escala geográfica y afectan a la organización social y territorial de las comunidades, plasmándose en unas relaciones de dominación e incluso de opresión que afectan cotidianamente a muchas personas con discapacidades (Abberley, 1987; Imrie, 1996: 5) y no todas esas personas tienen ni la capacidad ni los recursos para resistir a los procesos de exclusión y de opresión social (Kitchin, 1998: 354; Thomas, 2007: 10-11). En la década de 1970, distintas ciencias del territorio vinculadas a la planificación urbana, a la geografía o a la arquitectura comenzaron a manifestar cierto interés en el modo cómo los espacios construidos por el ser humano podrían ser más accesibles a las personas con diversidad funcional, para facilitar así su movilidad, particularmente en zonas urbanas de Europa, Norteamérica y Australia (Gleeson, 1999: 1; McEwan y Butler, 2007: 448). Más adelante, y en un contexto de giro cultural común a las ciencias sociales y humanas, estas disciplinas territoriales analizaron los entornos cotidianos y los factores ambientales que influyen en la asunción de las funciones básicas ${ }^{1}$ y de derechos de las personas en sus espacios de existencia: vivir en comunidad, la vida en el hogar, la actividad laboral, el acceso al consumo y a los servicios, la formación y la educación, la disposición de tiempo y de espacios para el ocio y el esparcimiento y, por último, el desplazamiento físico para llevar a cabo todas estas actividades. Se emplearon los modelos más usuales en el estudio científico-académico de la discapacidad: el médico o individual, el social, el biopsicosocial y el de capacidades, los cuales cuestionaron la concepción "precientífica» o tradicional de la discapacidad, creada por la religión y la cultura de muchas sociedades que la consideraban como un castigo o el resultado de una ira ancestral o divina (Coleridge, 1993: 71-72). Esta concepción ha cargado secularmente de estigmas a una parte considerable de la población que padecía alguna de ellas.

Diversos trabajos pioneros de una geografía de la discapacidad emplearon herramientas de análisis espacial para la descripción y la explicación del reparto, la incidencia y la prevalencia de patologías o de espacios que generan (o aumen$\tan )$ las discapacidades. Dichas investigaciones se basan en planteamientos de raigambre positivista y están orientadas a la planificación urbanística de la discapacidad a través de la aplicación de modelos ecológicos que identifican las zonas en las que reside y se desenvuelve la población con diversidad funcional (Kitchin, 2000: 18). Parten de la idea de que la discapacidad es un fenómeno personal al que es necesario adaptarse (Dorn y Keirns, 2010: 101), ya que la población que la padece no es un grupo homogéneo (Grech, 2014: 59).

Por el contrario, bajo planteamientos materialistas, el modelo social ha investigado la discapacidad con el propósito de desmantelar las barreras socia-

1. Las Daseinsgrundfunktionen ('funciones básicas de las personas') constituyen el marco teórico de referencia de la Escuela de Geografía Social de Múnich. Explican cuáles son las necesidades que tienen las personas en los lugares y en los espacios en los que se desenvuelven. 
les y ambientales que dificultan la participación de las personas con diversidad funcional, mediante el cambio social y el reconocimiento de derechos por parte del conjunto de la sociedad (Gregory et al., 1981: 164-165). Sobre este planteamiento, la discapacidad es el resultado de un desarrollo económico y social desigual: «[...] la deficiencia en los países pobres es resultado directo de un desarrollo económico y social sesgado y basado en la explotación» (Barnes, 2010: 14), y, por lo tanto, generador de un círculo vicioso que engloba pobreza y discapacidad (Mitra, 2006: 244; Eide e Ingstad, 2011: 5). En consecuencia, y siguiendo a Barnes y Sheldon (2010: 771), las economías de mercado han elevado las desigualdades dentro y fuera de los países, y especialmente en los denominados "países del sur», cuya tendencia a la exclusión social y a la marginalidad es aún mayor (Grech, 2014: 52-53). Así, este modelo de discapacidad plantea un debate entre deficiencia y discapacidad (Barnes y Mercer, 2010: 92-93), en el que, desde un punto de vista médico, las deficiencias serían las limitaciones funcionales (físicas, mentales o sensoriales) de una persona, mientras que, desde un punto de vista social, la discapacidad sería la pérdida o la limitación de oportunidades para participar en la vida comunitaria en igualdad de condiciones. En las sociedades del bienestar, esta última concepción de la discapacidad favorece la toma de conciencia y el advenimiento de una identidad diversa de las poblaciones con discapacidad, que, junto a sus familiares y otras personas solidarias, se caracterizan por ser unas comunidades con relativa influencia política (Olivera, 2006: 527), ya que, al margen de sistemas asistenciales, sus demandas giran en torno a cuestiones vinculadas al nivel de ingresos, el empleo o los derechos civiles, entre otras, lo que ha supuesto que estas comunidades sean consideradas un nuevo movimiento social (Knox y Pinch, 1982: 325).

Otros planteamientos postestructurales han procurado hacer comprensibles las experiencias «de los distintos cuerpos con discapacidad» en los lugares de producción y reproducción social. Ello presupone una nueva perspectiva del modelo social de la discapacidad hacia concepciones más centradas en la vida cotidiana de las personas que pugnan con sus cuerpos y sus mentes en la sociedad y en los lugares donde se desenvuelven: el hogar, Internet, el trabajo, etc. (Chouinard et al., 2010: 7). Es en ese punto cuando las ciencias del territorio abordan la discapacidad a una escala de detalle, pasando del nivel de barrio al de hogar (Dyck, 2011: 358). Esta concepción entronca con el modelo biopsicosocial de discapacidad que, por un lado, distingue entre los factores médicos que explican la disfunción física provocada por la enfermedad y, por otro lado, distingue entre las barreras discapacitantes, las normas sociales o las relaciones de poder desigual que contribuyen a generar o a incrementar la discapacidad.

Estos modelos de discapacidad, cimentados en paradigmas positivistas, marxistas o postestructurales, no deben ser entendidos de manera secuencial como si los más recientes se apoyasen en los más antiguos. Al contrario, todos ellos son complementarios y se insertan en un proceso de cambio de paradigma en la consideración de la discapacidad. No en vano, y desde una perspectiva más amplia, el modelo de capacidades de Amartya Sen ofrece una base teórica útil capaz de integrar, desde un punto de vista holístico, la discapacidad en 
un entorno global y local (Organización Mundial de la Salud, 2011: 12). En dichos entornos, la diversidad funcional engloba deficiencias, limitaciones de la actividad y restricciones a la participación, de manera que la discapacidad será un factor clave de desventaja y exclusión social a cualquier escala geográfica: «El enfoque de capacidades [...] destaca los derechos humanos y el desarrollo como libertad, y fomenta el concepto de que la pobreza de las personas con discapacidad [...] abarca la exclusión social y la privación de participación, y no sólo la falta de recursos materiales» (Organización Mundial de la Salud, 2011: 12). Pese a que el enfoque de capacidades se ha empleado a nivel internacional para analizar la relación entre la discapacidad, la pobreza y la desigualdad de género, su utilidad a la hora de formular políticas de discapacidad no se ha considerado (Mitra, 2006: 236), lo cual es un hecho de suma importancia, porque su influencia se puede observar en indicadores multidimensionales de bienestar, como el índice de desarrollo humano o el índice de empoderamiento femenino, entre otros (Palmer, 2011: 211).

Bajo este razonamiento, en el que se pone de manifiesto el carácter trasversal y multiescalar de la discapacidad, conviene examinar la enorme influencia que tienen los factores sociales y culturales en la construcción (producción y reproducción) de las geografías de la discapacidad, particularmente teniendo en cuenta las repercusiones en cuanto a exclusión social que de ellos se derivan, pues es evidente que, a cualquier escala geográfica, los lugares y/o los territorios son espacios en los que se puede manifestar la exclusión social: «[...] la exclusión social puede ser entendida como una acumulación de procesos concluyentes con rupturas sucesivas que [...] van alejando e interiorizando a personas, grupos, comunidades y territorios con respecto a los centros de poder, los recursos y los valores dominantes» (Estivill, 2003: 19-20), y en los que, mediante las técnicas y las fuentes de información apropiadas, identificar, caracterizar y comparar a los colectivos de población más vulnerable y dependiente, como es el caso de la población con discapacidades o con diversidad funcional.

\section{La definición de la discapacidad: factores, conceptualización $\mathrm{y}$ disparidades en las fuentes de información}

El ambiente natural y el entorno construido por el ser humano devienen en muchas ocasiones en barreras que, junto con otros factores, dificultan o impiden la autonomía de las personas con minusvalidez. El Informe mundial sobre la discapacidad señala que también hay otros aspectos que, junto a los individuales y ambientales, inciden directamente en la salud de estas personas. Se trata del acceso al agua potable y al saneamiento, de la correcta nutrición, de la pobreza, de las condiciones laborales, del clima o de la atención médica, los cuales muestran un complejo panorama de retos compartidos con múltiples dimensiones que inciden en el bienestar social de la población en general y de la población discapacitada en particular, y en cuya base se halla la superación de las enormes desigualdades entre sociedades y territorios: «[...] la desigualdad es una de las principales causas de mala salud y, en consecuencia, de discapa- 
cidad» (Organización Mundial de la Salud, 2011: 4). Además, este planteamiento que genera desigualdad para la población con discapacidad se puede presentar también para otros colectivos de población vulnerable por motivos de género, edad o sexualidad, entre otros (Chouinard et al., 2010: 14).

Si la caracterización de la discapacidad, ya sea de modo cuantitativo o cualitativo, o bajo enfoques médicos o sociales, ha supuesto tradicionalmente una falta de consenso entre profesionales e investigadores debido a la diversidad de enfoques o al proceso de construcción social de la discapacidad (Puga y Abellán, 2004: 17-23), su medición espacial también presenta enormes dificultades, especialmente en lo que respecta a su escala de análisis. En efecto, y pese a los resultados dispares que ofrecen los organismos que generan información estadística acerca del número de personas que vive en el mundo con alguna minusvalidez ${ }^{2}$, es fácilmente comprensible la tendencia a su progresivo incremento y a una agudización de las diferencias entre colectivos de población discapacitada. Ello es debido a la creciente polarización social como resultado del cuestionamiento de los estados como garantes de la protección social, del envejecimiento demográfico o de las mayores tasas de supervivencia respecto a enfermedades infecciosas, enfermedades crónicas no transmisibles y lesiones. En ese sentido, son numerosos los estudios que, a nivel mundial, profundizan en la relación entre el envejecimiento y la discapacidad o la calidad de vida en edades más avanzadas (Lynch et al., 2009; Rojo-Pérez et al., 2015), o como, a nivel estatal, sucede con los Informes del envejecimiento en red. Por otro lado, y sobre la base de los datos ofrecidos por la Organización Mundial de la Salud en el Informe mundial sobre la discapacidad, existe una distribución geográfica desigual de las patologías y, especialmente, de los años de salud perdidos como consecuencia de la discapacidad que añade más argumentos a la consolidación de un mundo asimétrico y en el que la minusvalidez desempeña, cada vez más, un factor de primer nivel a la hora de explicar las desigualdades sociales.

Tanto el reparto geográfico de los años de vida ajustados por discapacidad $(\mathrm{AVAD})^{4}$ como la prevalencia de la discapacidad, entendida esta como la pro-

2. Las estimaciones que, en el periodo 2002-2004, ofrece la Encuesta mundial de salud apuntan que la prevalencia de discapacidad asciende al $15,6 \%$ de la población mundial, mientras que el estudio sobre la Carga mundial de morbilidad del año 2004 sitúa el porcentaje en un 19,4\%. En ambos casos, se utilizaron métodos distintos para realizar las estimaciones, hecho que dificulta su comparación.

3. Desde el año 2003, el Departamento de Población del Instituto de Economía, Geografía y Demografía del CSIC elabora informes de carácter divulgativo acerca de indicadores estadísticos y procesos sociales vinculados al envejecimiento de la población mundial en general y de la de España en particular. A partir del año 2013, dichos informes aparecen recogidos en el portal Envejecimiento en red (<http://envejecimiento.csic.es/documentacion/ index.htm>).

4. Años de vida ajustados por discapacidad (AVAD) es un indicador elaborado por la Organización Mundial de la Salud que mide la carga o el peso que, para una población teórica de 100.000 individuos, tiene la mala salud, la discapacidad o la muerte prematura. En su elaboración, se consideran los años de vida perdidos por una muerte prematura (AVP) y los años vividos con discapacidad (ADP). 


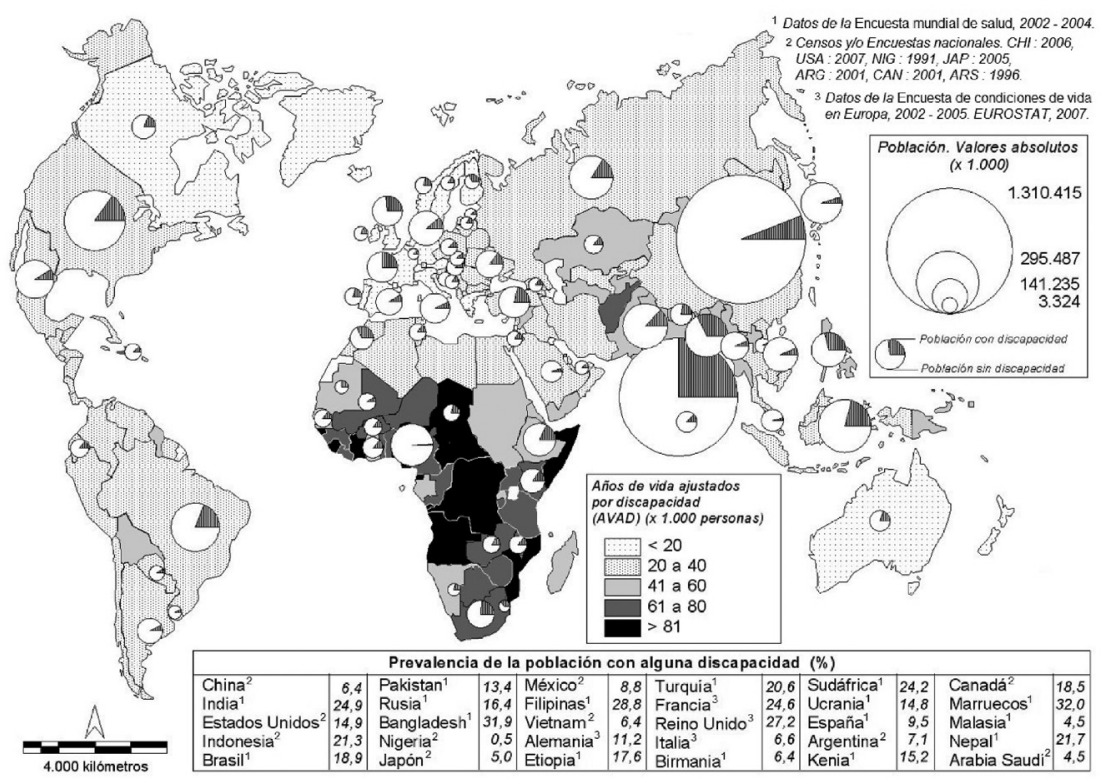

Figura 1. Distribución mundial de la prevalencia de la población con discapacidades (\%) y de los años de vida ajustados por discapacidad (por cada 100.000 personas).

Fuente: OMS, Informe mundial sobre la discapacidad, 2011. Los países representados corresponden a los 59 en los que se realizó la Encuesta mundial de salud para el periodo 2002-2004. Elaboración propia.

porción de individuos de una población que, en un momento dado, presentan minusvalidez, han mostrado tradicionalmente algunas limitaciones, con independencia de la escala de análisis. En esencia, estas se han fundamentado en una doble problemática (figura 1).

La primera problemática es inherente a la propia conceptualización del término discapacidad y a las diferencias que ha suscitado su definición entre la comunidad científica, especialmente a la hora de establecer qué indica dicha palabra y en qué ámbitos opera. A partir de la definición propuesta por la Organización Mundial de la Salud: Clasificación internacional del funcionamiento de la discapacidad y la salud (CIF) en 2001, y con un gran consenso por parte de los especialistas, ha de entenderse la discapacidad como un "concepto que engloba deficiencia, limitación en la actividad y restricción en la participación». No obstante, y al margen de las definiciones más recurrentes, es preciso destacar que la concepción de la discapacidad, o de una deficiencia, varía mucho según los países o las culturas de que se trate, por lo que su percepción o la respuesta social o familiar ante esta será muy diferente (Barnes, 2010: 13) y ello tendrá consecuencias posteriores a la hora de su medición. Asímismo, es preciso hacer hincapié en el carácter heterogéneo del concepto discapacidad, 
que es asumido por la CIF5, pues esta considera una variedad de indicadores y de factores que deben medir las limitaciones derivadas de los distintos grados de diversidad funcional. Se trata, por lo tanto, de una clasificación de carácter multidimensional, que engloba aspectos que van desde el funcionamiento de las estructuras corporales, de las capacidades sensoriales, de los mecanismos sociales y comunitarios orientados a la consecución de las actividades básicas de la vida diaria y de los factores ambientales, ya sean estos dispositivos, actitudes o el medio físico, aspectos todos ellos que no han sido considerados de igual manera ni en el tiempo ni en todos los lugares. Así, a diferencia de la mortalidad (endógena o exógena), que se puede medir fácilmente porque es un fenómeno absoluto, no sucede lo mismo con la discapacidad, precisamente por su raigambre heterogénea y su consideración relativa. De hecho, tal y como demostraron Robine et al. (1991) para algunos países occidentales, el incremento de la esperanza de vida no implica que los años de existencia sana aumenten con la misma intensidad, pues, durante ese tiempo "ganado", crece la morbilidad y, por lo tanto, las situaciones de dependencia de las personas con discapacidad. Se demuestra que los distintos grados de dependencia van a condicionar a cualquier escala geográfica la evolución en la prevalencia de la minusvalidez.

La segunda problemática, estrechamente vinculada a la anterior, se basa en las enormes dificultades que entraña la recogida de información y producción estadística. En consecuencia, es complicado homogeneizar datos para realizar comparaciones longitudinales y análisis socioterritoriales del fenómeno. Este hecho ya fue advertido por la Organización Mundial de la Salud a comienzos de la década de 1980, cuando propuso una clasificación de la discapacidad de raigambre médica: la Clasificación internacional de las deficiencias, discapacidades y minusvalías (CIDDM). En ella, ya se proponía el establecimiento de un sistema de recogida de datos que identificase las metodologías empleadas por disciplinas que preparan estadísticas sobre discapacidad, para establecer un marco común de cara a su futuro desarrollo (Naciones Unidas, 1990: 3-4). Como resultado de esa necesidad de información, y con el impulso que supuso la CIF, se elaboraron las dos grandes fuentes internacionales de información estadística sobre discapacidad: la Encuesta mundial de salud de la OMS para el periodo 2002-2004, que actualiza datos estadísticos de DISTAT (Disability Stastistic Database) que las Naciones Unidas recogieron hasta el año 1994, y el informe Carga mundial de morbilidad del año 2004. Ambas fuentes, junto a estudios regionales como las encuestas de condiciones de vida en Europa, las encuestas nacionales sobre discapacidad, las encuestas a hogares sobre las condiciones de vida y salud o la información

5. Para identificar el tipo de discapacidad, la CIF utiliza dos niveles. En un primer nivel, existen 30 capítulos que agrupan los ámbitos en los que operan las limitaciones, particularmente en relación con el cuerpo humano, los sentidos, las facilidades para desempeñar las ABVD y el medio en el que se desenvuelven las personas en relación con el diseño universal. En un segundo nivel, se presentan, para cada uno de esos treinta capítulos, las condiciones o los supuestos que posibilitarían las afecciones (hasta 362) en las que aparecerían, en distintos grados, las situaciones de diversidad funcional. Véase en $<$ http://www.imserso.es/InterPresent2/groups/imserso/documents/binario/435cif.pdf $>$. 
Tabla 1. Prevalencia de población discapacitada sobre la población total (\%) y años vividos con discapacidad en los países latinoamericanos (YLD)*. Varios años

\begin{tabular}{|c|c|c|c|c|c|c|c|c|c|}
\hline \multicolumn{5}{|c|}{ Prevalencia de la discapacidad ${ }^{* *}$} & \multicolumn{5}{|c|}{ Prevalencia de la discapacidad } \\
\hline & $\begin{array}{c}\text { Encuesta } \\
\text { mundial } \\
\text { de salud }(\%)\end{array}$ & $\begin{array}{c}\text { Censos } \\
\text { nacionales } \\
(\%)\end{array}$ & $\begin{array}{c}\text { Otras } \\
\text { encuestas } \\
(\%)\end{array}$ & $\begin{array}{c}\text { YLD } \\
\text { (años) }\end{array}$ & & $\begin{array}{c}\text { Encuesta } \\
\text { mundial } \\
\text { de salud (\%) }\end{array}$ & $\begin{array}{c}\text { Censos } \\
\text { nacionales } \\
(\%)\end{array}$ & $\begin{array}{c}\text { Otras } \\
\text { encuestas } \\
(\%)\end{array}$ & $\begin{array}{c}\text { YLD } \\
\text { (años) }\end{array}$ \\
\hline Argentina & & 7,1 & & 8,7 & Haití & & 1,5 & & 11,7 \\
\hline Bolivia & & 3,1 & 3,9 & 10,8 & Honduras & & 1,8 & 2,6 & 9,5 \\
\hline Brasil & 18,9 & 14,9 & 1,8 & 10,1 & México & 7,5 & 1,8 & 8,8 & 8,2 \\
\hline Chile & & 2,2 & 12,9 & 8,1 & Nicaragua & & & 10,3 & 8,5 \\
\hline Colombia & & 6,4 & 5,6 & 10,2 & Panamá & & 1,8 & 11,3 & 8,4 \\
\hline Costa Rica & & 5,4 & 7,8 & 7,9 & Paraguay & 10,4 & 1,1 & 3,0 & 9,4 \\
\hline Cuba & & 4,2 & 7,0 & 8,2 & Perú & & 10,9 & 8,7 & 9,4 \\
\hline Ecuador & 13,6 & 4,6 & 12,1 & 9,2 & R. Dominicana & 11,1 & 4,2 & 2,0 & 9,8 \\
\hline El Salvador & & 1,8 & 1,5 & 9,8 & Uruguay & 4,6 & & 7,6 & 9,0 \\
\hline Guatemala & & 6,2 & 3,7 & 10,0 & Venezuela & & 4,2 & & 9,1 \\
\hline
\end{tabular}

* De entre los indicadores sintéticos de salud que se recogen en el Informe mundial sobre discapacidad, se ha optado por utilizar aquellos que se derivan del método de Sullivan acerca del cálculo de la esperanza de vida con o sin discapacidad. En concreto, se han seleccionado los años vividos con discapacidad (YLD), que mide el mal estado de salud que representan para una población las enfermedades y las minusvalías. Este indicador, que está basado en la tabla de mortalidad, está estandarizado por edades, lo que permite comparar los resultados entre distintos países, al no estar afectado por la estructura por edades de la población.

YLD (Years Lived with Disability). Se ha optado por mantener la denominación de este indicador en inglés. En la versión en castellano del Informe mundial sobre discapacidad, el término empleado es ADP (años de salud perdidos por la discapacidad).

** Las fuentes de información acerca de la prevalencia de la discapacidad son, por países y años, los siguientes: Argentina (censo: 2001), Bolivia (censo: 2001, encuesta: 2001), Brasil (censo: 2000, encuesta: 1981), Chile (censo: 2002, encuesta: 2004), Colombia (censo: 2005, encuesta: 1991), Costa Rica (censo: 2000, encuesta: 1998), Cuba (censo: 2003, encuesta: 2000), Ecuador (censo: 2001, encuesta: 2005), El Salvador (censo: 1992, encuesta: 2003), Guatemala (censo: 2002, encuesta: 2005), Haití (censo: 2003), Honduras (censo: 2000, encuesta: 2002), México (censo: 2000, encuesta: 2002), Nicaragua (encuesta: 2003), Panamá (censo: 2000, encuesta: 2005), Paraguay (censo: 2002, encuesta: 2002), Perú (censo: 2007, encuesta: 2006), República Dominicana (censo: 2002, encuesta: 2007), Uruguay (encuesta: 2004) y Venezuela (censo: 2001).

Fuente: OMS, Informe mundial sobre la discapacidad, 2011. Elaboración propia.

recogida en algunos censos nacionales, han constituido una importante base de información secundaria a partir de la cual se ha podido investigar sobre la distribución geográfica de la discapacidad. Sin embargo, y a diferencia de la dificultad que supuso su conceptualización, la homogeneidad y la fiabilidad de los datos de información estadística disponible sobre la prevalencia de discapacidad por países (o regiones) no siempre ha sido la deseada, ya fuera por las deficiencias en la recogida de datos, por los errores de muestreo, por su desagregación o por la falta de un criterio uniforme a la hora de definir la minusvalidez, entre otros motivos. Un claro ejemplo de las divergencias que, para un mismo país, ofrecen los datos estadísticos acerca de la prevalencia de la discapacidad se puede observar al comparar los registros que, para los estados latinoamericanos, ofrece la Encuesta mundial de la salud, con los censos nacionales respectivos o con las encuestas específicas a personas u hogares sobre discapacidad o estado de salud que elaboran los servicios de información estadística de los países respectivos (tabla 1). 
En efecto, las enormes disparidades que, en políticas de atención a la discapacidad, se producen entre estos países es un reflejo de las diferencias económicas, demográficas, sanitarias o culturales que existen entre ellos. Esta heterogeneidad de resultados precisa, en la línea de lo señalado por la Organización Panamericana de la Salud (2012: 33-34), de una revisión y una actualización exhaustivas en torno a la aplicación de los parámetros establecidos por la CIF a la hora de clasificar las discapacidades. Todo ello conforma un panorama en el que los datos estadísticos no reflejan el verdadero alcance de la discapacidad, pues esta suele alcanzar un nivel superior al que las cifras estadísticas recogen. No en vano, la mejora en la recopilación de los datos sobre discapacidad es una de las recomendaciones que el Informe mundial sobre la discapacidad (2011: 302) apunta como necesaria de cara a la planificación integral de políticas sobre discapacidad.

\section{Los años vividos con discapacidad y su relación con indicadores de desarrollo humano}

Aun considerando las limitaciones que tienen las estimaciones sobre discapacidad a nivel internacional, cabe indagar acerca de los factores socioeconómicos y de las dinámicas territoriales que, de manera independiente, muestran comportamientos similares cuando se trata de analizar la realidad sociogeográfica de la discapacidad. A escala internacional, y según el Informe mundial sobre la discapacidad o los planteamientos teóricos basados en enfoques sociales acerca de esta y en el enfoque de capacidades, las actuales tendencias de bienestar social reflejan importantes diferencias entre regiones que, en mayor o menor grado, también se pueden extrapolar a las condiciones de vida de la población con diversidad funcional.

Sobre la base documental y estadística de los informes de desarrollo humano que elabora el Programa de las Naciones Unidas para el Desarrollo (PNUD), se puede identificar una serie de indicadores genéricos que permiten su estandarización y comparación con los indicadores del estudio Carga mundial de morbilidad $\mathrm{u}$ otra información sobre discapacidad y enfermedades recogida en censos y/o en encuestas nacionales centradas en los años vividos con discapacidad. En este trabajo y bajo planteamientos prospectivos, se seleccionan, por un lado, una serie de variables que permiten clasificar a los 187 países sobre los que se dispone de información completa acerca de la distribución geográfica de la discapacidad: los años vividos con ella (YLD). Por otro lado, se toma en consideración una serie de variables independientes vinculadas al desarrollo humano de las poblaciones de 135 países: la esperanza de vida al nacer (EPV), el promedio de años de escolaridad en los adultos a partir de 25 años (MYS), la renta per cápita (RTA), el índice de desigualdad de género (IDG) y la tasa de población urbana (URB).

6. En el estudio, se han descartado aquellos países que no alcanzan el millón de habitantes o bien aquellos para los que no se dispone de información completa, particularmente del índice de desigualdad de género (IDG). 


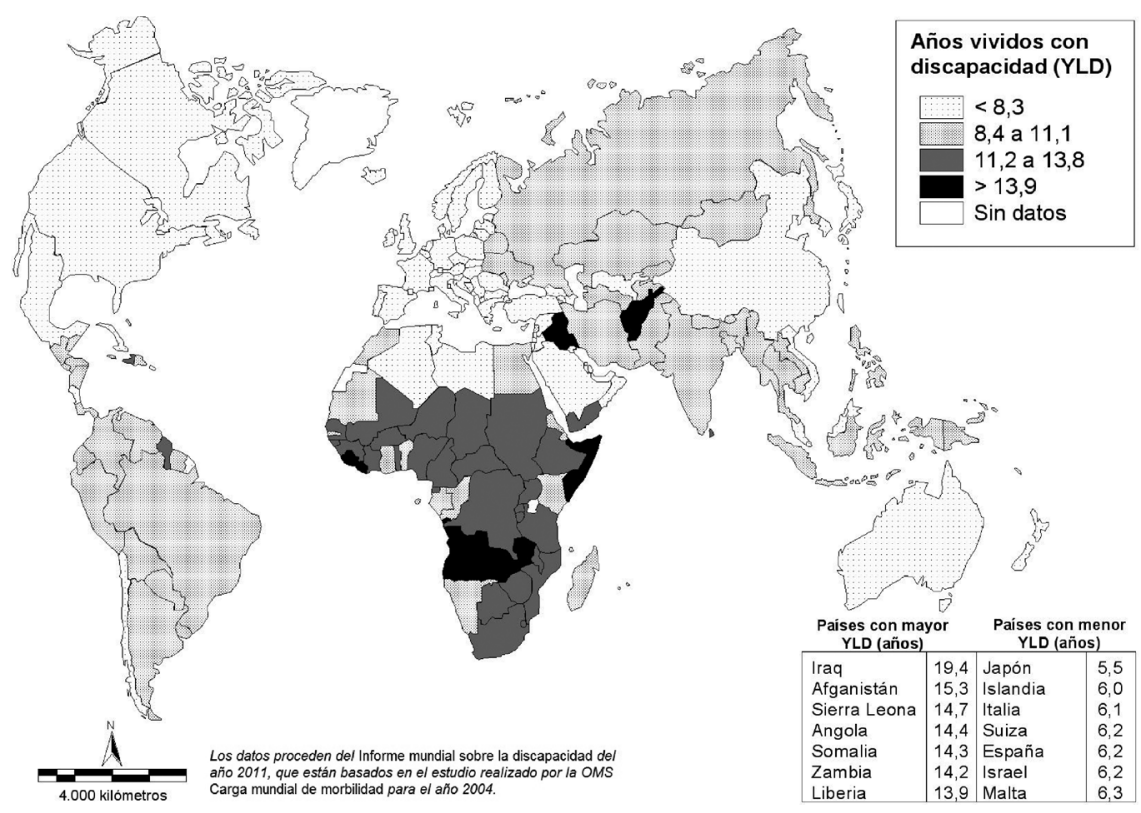

Figura 2. Distribución mundial de los años vividos con discapacidad (YLD). Años

Fuente: OMS, Informe mundial sobre la discapacidad, 2011. Elaboración propia.

Se trata de indicadores que, relacionándolos también con la prevalencia de población discapacitada, abarcarían las dimensiones del bienestar social propuestas por Keyes (1998: 122-123), puesto que el objetivo en la elaboración de los citados indicadores es medir aspectos vinculados a la igualdad de oportunidades y al acceso a la renta, a la educación o a la atención sanitaria, entre otros, y por lo tanto permiten indagar acerca de la integración social, la aceptación social, la contribución social, la actualización social y la coherencia social de las personas, cuya calidad de vida se ve menguada por la diversidad funcional y las posibles restricciones en la atención a la dependencia. Se trata, por lo tanto, de una selección de indicadores multidimensionales para estudiar el desarrollo humano que pueden combinarse para medir la distribución y el impacto de la minusvalidez en los países (Mitra et al., 2013).

En efecto, la distribución geográfica de los años vividos con discapacidad permite aproximarse a los desequilibrios sociales a escala global (figura 2). Ello se constata al valorar cuáles son los países que registran un mayor coeficiente de este indicador: Iraq o Afganistán en Asia ; Sierra Leona, Angola, Somalia, Zambia y

7. A pesar de esta distribución de los años vividos con discapacidad que muestra el Informe mundial sobre la discapacidad de 2011, hay que tener en cuenta que conflictos como el de Siria en Oriente Próximo han supuesto, según la Agencia de las Naciones Unidas para los Refugiados (ACNUR), además de 6,5 millones de desplazados, un aumento de la población 
Liberia en África, o Haití en América Latina. Es decir, estados que, discapacidades al margen, presentan un alarmante grado de emergencia social lastrado por años de guerras, crisis alimentarias, sanitarias, educativas, políticas y ambientales. $\mathrm{Al}$ otro extremo de este mundo mayoritario, se sitúan buena parte de los países llamados "desarrollados», cuyos bajos niveles de años vividos con discapacidad contrastan con las dispares políticas sociales y de atención a la dependencia que se llevan a cabo en cada uno de ellos (Rodríguez, 2011; Palència et al., 2014).

Es evidente, sin embargo, que, bajo esta distribución de años vividos con discapacidad, existe un claro paralelismo con la prevalencia de personas con discapacidad, aunque bastante matizada según cual sea la fuente de información y/o el grado de envejecimiento de la población del país. Llegados a este extremo, y sobre los planteamientos de Coleridge (1993: 64-65), cabe hacer hincapié en dos aspectos clave: en primer lugar, que las deficiencias no se limitan solo a las personas pobres y, en segundo lugar, que la mejora de la salud en los países industrializados conduce a una mayor prevalencia de la discapacidad, porque las personas viven el tiempo suficiente para adquirir las deficiencias que discapacitan.

En ese sentido, la Encuesta mundial de la salud señala que el 15,6\% de la población mundial presenta algún tipo de discapacidad (figura 1), siendo esta más prevalente en países como Marruecos, Bangladesh, Filipinas o India, cuyos registros superan ampliamente la media mundial. Sin embargo, establecer consideraciones generales en torno al desarrollo de regiones o de sociedades prestando atención a conjuntos de variables aisladas y sin tener en cuenta su diversidad interna puede ser aventurado. Mucho más cuando las fuentes de información no están homogeneizadas y su fiabilidad no es la deseada.

\section{Planteamiento metodológico y resultados}

En este punto, el presente trabajo tiene como objetivo comprobar si, a una escala geográfica internacional, los indicadores independientes seleccionados explican estadísticamente los valores registrados en los años vividos con discapacidad (YLD) de los países considerados. Para ello, se parte inicialmente de una matriz de correlación $(r)$, a fin de comprobar el grado de relación de todas las variables entre sí, teniendo presente que la existencia de correlación no significa causalidad, es decir, que aunque dos fenómenos estén relacionados, ello no supone que uno sea la causa de otro (tabla 2).

Pese a que la matriz de correlación de Pearson presenta puntuaciones notablemente elevadas para las variables seleccionadas, no se puede afirmar empíricamente que estas estén correlacionadas. En el mejor de los casos, se podrá señalar cuáles son las que muestran un comportamiento más o menos dispar desde un punto de vista estadístico.

discapacitada, especialmente entre los niños. A ese respecto, existen dos informes: Living in the Shadows, sobre las condiciones de vida de los refugiados sirios en el Líbano, y Syrian refugees with disabilities living in camps in northern Iraq. Ambos están disponibles en el sitio web de ACNUR. 
Tabla 2. Matriz de correlación de Pearson para los indicadores seleccionados*

\begin{tabular}{|c|c|c|c|c|c|c|}
\hline & YLD & EPV & MYS & RTA & IDG & URB \\
\hline YLD & 1,0000 & & & & & \\
\hline EPV & $-0,8649$ & 1,0000 & & & & \\
\hline MYS & $-0,7312$ & 0,7391 & 1,0000 & & & \\
\hline RTA & $-0,6786$ & 0,6794 & 0,6958 & 1,0000 & & \\
\hline IDG & 0,8060 & $-0,7856$ & $-0,8203$ & $-0,7856$ & 1,0000 & \\
\hline URB & $-0,6141$ & 0,6847 & 0,6379 & 0,6821 & $-0,5757$ & 1,0000 \\
\hline
\end{tabular}

Significado de las siglas: YLD: años vividos con discapacidad, EPV: esperanza de vida al nacer, MYS: media de años de escolaridad, RTA: renta per cápita, IDG: índice de desigualdad de género y URB: porcentaje de población urbana.

* Por el valor que tiene en cuanto a la medición del bienestar y el desarrollo de las poblaciones, se consideró en un primer momento introducir el índice de desarrollo humano en el modelo de análisis. Sin embargo y para evitar los problemas de multicolinealidad, se optó por desagregar el citado indicador en las tres variables que lo componen: EPV, MYS y RTA. Bajo este planteamiento, no se estarían introduciendo variables con una elevada correlación entre sí y, sobre todo, no se estaría introduciendo una misma variable dos veces para obtener el modelo explicativo más ajustado en relación con la distribución geográfica de los años vividos con discapacidad.

Fuente: OMS, Informe mundial sobre la discapacidad, 2011. PNUD, Informe sobre el desarrollo humano, 2014. ONU, World Urbanization Prospects, the revision 2014, 2014. Elaboración propia.

Sin embargo, y debido a la importancia que tiene el reparto geográfico desigual de las variables anteriormente citadas para el bienestar social de la población, se ha realizado también un análisis de regresión lineal múltiple mediante el método de mínimos cuadrados. El propósito es averiguar el efecto simultáneo que, sobre los años vividos con discapacidad $(y)$, tienen las cinco variables independientes $\left(x_{1}, x_{2}, x_{3}, x_{4}\right.$ y $\left.x_{5}\right)$ y cuáles de estas explicarían (o no) el coeficiente de determinación múltiple ajustado más elevado $\left(R^{2}\right)$ en relación con la variable dependiente $(y)$. En el caso estudiado, ello sirve para construir una tabla en la que presentar los valores que permiten realizar la ecuación de regresión (tabla 3).

Los resultados alcanzados muestran que son la EPV $\left(x_{1}\right)$ y el IDG $\left(x_{2}\right)$, en cualquiera de los supuestos, las variables que mejor miden la bondad de ajuste para llegar a la ecuación estimada de regresión múltiple $\left(y=18,2477-0,1498 x_{1}\right.$ $+4,2387 x_{2}$ ), habiéndose descartado los años promedio de escolaridad, la renta per cápita y la tasa de población urbana, debido a que su inclusión en el modelo no hace aumentar el valor de $R^{2}$ y porque estas observaciones no aportan suficientes evidencias para explicar la hipótesis inicial. Teniendo en cuenta esta inferencia y sobre la muestra de países incluidos en este modelo, se puede interpretar que el $78,7 \%$ de los años vividos con discapacidad $(y)$ vienen explicados por estas dos variables. Pero es evidente que dicho resultado no es suficiente para sostener que la distribución de las causas que implican una mayor o menor prevalencia de los años vividos con discapacidad a escala internacional se expliquen únicamente por las situaciones sociales, económicas, ambientales o culturales que subyacen bajo estas dos variables. Entre otras consideraciones, porque el ámbito de análisis es muy grande, porque no se han incluido más indicadores desagregados de desarrollo o sociodemográficos (como, por ejemplo, podrían ser la rama de la actividad 
Tabla 3. Resultado de la regresión lineal y múltiple de las variables seleccionadas*

\begin{tabular}{|c|c|c|c|c|c|}
\hline & \multicolumn{5}{|c|}{ Coeficiente de correlación de Pearson (valor de $r$ ) } \\
\hline & EPV & IDG & MYS & RTA & URB \\
\hline \multirow[t]{3}{*}{$\underline{\text { YLD }}$} & $-0,8649$ & 0,8060 & $-0,7312$ & $-0,6786$ & $-0,6141$ \\
\hline & \multicolumn{5}{|c|}{ Regresión lineal simple (valor de $R^{2}$ ajustado) } \\
\hline & $x_{1}=\mathrm{EPV}$ & $x_{2}=$ IDG & $x_{3}=\mathrm{MYS}$ & $x_{4}=\mathrm{RTA}$ & $x_{5}=\mathrm{URB}$ \\
\hline YLD (y) & 0,7461 & 0,6471 & 0,5312 & 0,4564 & 0,3725 \\
\hline \multicolumn{6}{|c|}{ Regresión lineal múltiple $R^{2}$ (ajustado) } \\
\hline YLD + EPV & & & & & 0,7461 \\
\hline YLD + EPV + IDG & & & & & 0,7867 \\
\hline YLD + EPV + IDG + & MYS & & & & 0,7856 \\
\hline YLD + EPV + IDG + & MYS + RTA & & & & 0,7841 \\
\hline$\underline{Y L D}+E P V+I D G+$ & $M Y S+R T A+L$ & & & & 0,7824 \\
\hline \multicolumn{6}{|c|}{ Análisis de la varianza (coeficientes) } \\
\hline Intercepción (y) & $x_{1}$ & $x_{2}$ & \multicolumn{3}{|c|}{ Ecuación de regresión } \\
\hline 18,2477 & $-0,1496$ & 4,2387 & \multicolumn{3}{|c|}{$y=18,2477-0,1498 x_{1}+4,2387 x_{2}$} \\
\hline
\end{tabular}

Significado de las siglas: YLD: años vividos con discapacidad, EPV: esperanza de vida al nacer, IDG: índice de desigualdad de género, MYS: media de años de escolaridad, RTA: renta per cápita y URB: porcentaje de población urbana.

Fuente: OMS, Informe mundial sobre la discapacidad, 2011. PNUD, Informe sobre el desarrollo humano, 2014. ONU, World Urbanization Prospects, the revision 2014, 2014. Elaboración propia.

* También se planteó otra estrategia de análisis consistente en la reducción de las múltiples variables utilizadas (EPV, MYS, RTA, IDG y URB) para obtener una estructura factorial reducida mediante el método de extracción basado en el análisis de los componentes principales. Sin embargo, el resultado, con un porcentaje de la varianza explicada del $76,94 \%$, no resultó satisfactorio para este modelo de trabajo, a pesar de haber obtenido un único factor cuyo coeficiente de correlación $(r)$ con YLD era -0,8457 y su coeficiente de determinación simple $\left(R^{2}\right)$ de 0,7131 . Ello es debido a que, en una regresión múltiple en la que figurase el factor resultante del análisis multivariable, supondría de nuevo el mismo problema que con el IDH, es decir, se habría regresado dos veces la misma variable en el modelo de análisis, ya fuera por ella misma o como parte de una variable compuesta, y, por lo tanto, no se podría comprobar en una ecuación el peso de las variables independientes sobre los años vividos con discapacidad.

económica que mayor porcentaje aporta al PIB o el número de profesionales de la medicina y de los servicios sociales dedicados a la dependencia y/o a la discapacidad, entre otros) y, especialmente, porque este modelo presupone que el comportamiento de los individuos (sic países) es homogéneo en lo concerniente a la discapacidad y a las pautas de desarrollo. Esta manifiesta ambigüedad, sin embargo, permite, a partir de estas dos variables independientes, contribuir desde la geografía social y del bienestar a realizar una descripción geográfica regional de la distribución de los años vividos con discapacidad en relación con los patrones geográficos del desarrollo humano.

\section{Desarrollo y discapacidad: pautas en la distribución geográfica de la esperanza de vida al nacer e índice de desigualdad de género}

La relación entre la discapacidad de las poblaciones y el desarrollo se ha planteado mayoritariamente desde el enfoque de capacidades. En concreto, se ha 
orientado a la relación entre la pobreza y el estado de salud de las poblaciones urbanas de los países con mayores desigualdades internas (Montgomery y Hewett, 2005). Se ha realizado a través de análisis de regresión múltiple con variables vinculadas a la accesibilidad a los servicios sanitarios, las dotaciones y la habitabilidad de las viviendas, el nivel de estudios o el tamaño del municipio de residencia. Groce et al. (2011: 20-27), que recopilan hasta veintisiete publicaciones científicas que, desde 1989, han estudiado a nivel regional la relación entre la discapacidad y la pobreza, describiendo cuáles han sido los métodos empleados y los principales resultados. Aunque, a una escala de análisis más amplia, Palmer (2011:212) señala que la pobreza puede ser la causa de una deficiencia y apunta que aspectos como la nutrición insuficiente, las condiciones laborales desfavorables, la mala atención médica en la maternidad, el bajo peso al nacer, la deficiente cobertura inmunológica, las tasas más altas de analfabetismo, el desempleo (y el subempleo) y la movilidad profesional se asocian a mayores tasas de discapacidad.

En ese sentido, el hilo conductor que explicaría los diferentes registros observados en la distribución de los indicadores de desarrollo y discapacidad a nivel mundial se centra en las desigualdades políticas, sociales y económicas que subyacen a escalas más reducidas. Según McEwan y Butler (2007: 463): "There is thus a need for a more holistic and flexible approach to understanding disability, with a greater focus on local and individual experience and on recognizing the importance of geopolitical, social and cultural as well as economic contexts». En efecto, y mediante métodos de regresión múltiple para quince países en desarrollo, las investigaciones de Mitra et al. (2013) han podido demostrar que la discapacidad se asocia a la pobreza multidimensional, y especialmente en lo referente a un bajo nivel educativo, a las elevadas tasas de desempleo y a los mayores gastos médicos. Aspectos que, al margen de las estructuras demográficas de las poblaciones, son consecuencia de políticas de bienestar, actitudes sociales y comportamientos individuales inherentes al funcionamiento de las comunidades y de las sociedades, en un contexto de relaciones desiguales de poder a escala local y global.

\subsection{Años vividos con discapacidad y esperanza de vida al nacer}

A nivel mundial, existen trabajos que exploran la relación entre la esperanza de vida (sana) y la discapacidad bajo unos fundamentos basados en el enfoque de capacidades, como el de Salomon et al. (2013: 2157), que se plantea en términos de disparidades sociales: «Healthy life expectancy provides an alternative perspective on trends in inequality across countries». La mayoría de estos estudios se han centrado preferentemente en países desarrollados que cuentan con series de información demográfica y con estadísticas sobre la distribución de enfermedades bastante fiables, como es el caso de Estados Unidos, Australia, Reino Unido (Robine et al., 1991) o Francia (Cambois, Clavel, Romieu y Robine, 2008). En ese sentido, Lynch et al. (2009: 574) señalan la importancia que ha tenido en los países industrializados la aplicación del método de Sullivan en 


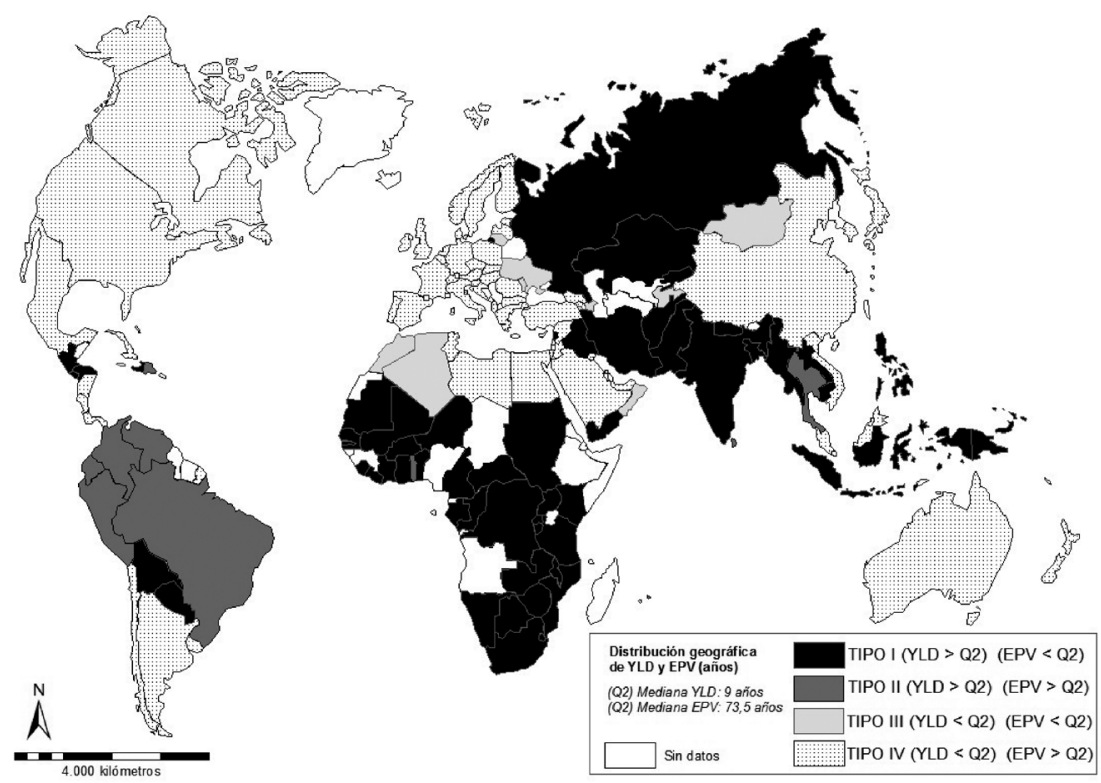

Figura 3. Distribución de los años vividos con discapacidad (YLD) y esperanza de vida al nacer (EPV).

Fuente: OMS, Informe mundial sobre la discapacidad, 2011. PNUD, Informe sobre el desarrollo humano, 2014. Elaboración propia.

la investigación sobre el envejecimiento y la vida libre de discapacidad. Apuntan que hay dos tipos de análisis centrados en la demografía de la discapacidad: por un lado, están los que analizan las posibilidades de discapacidad basadas en las tablas de mortalidad, mientras que, por otro lado, hay un segundo tipo de estudios que utilizan el análisis de regresión de datos de encuestas (normalmente nacionales), con el objetivo de explicar hipótesis sociológicas, psicológicas y gerontológicas respecto a la heterogeneidad del envejecimiento. Con este argumento, y sobre la base de los resultados de las regresiones obtenidas en este trabajo, se puede describir a nivel internacional una clasificación de países en los que poner en relación la distribución geográfica de los años vividos con discapacidad y la esperanza de vida al nacer (figura 3).

Esta distribución permite comprobar la relación lineal entre las variables YLD y EPV en la curva de regresión obtenida (figura 4). Según este modelo, el 74,6\% de los años vividos con discapacidad se podrían explicar con la esperanza de vida al nacer. Además, y teniendo en cuenta el gráfico de residuales, los valores atípicos observados (aquellos que se alejan dos desviaciones estándar de la distribución de los errores) solo representan el 2,96\% del modelo, lo cual permite suponer la validez de esta relación. En efecto, tan solo cuatro países (Irak, Yemen, Sri Lanka y Lesoto) presentan los valores más extremos que 

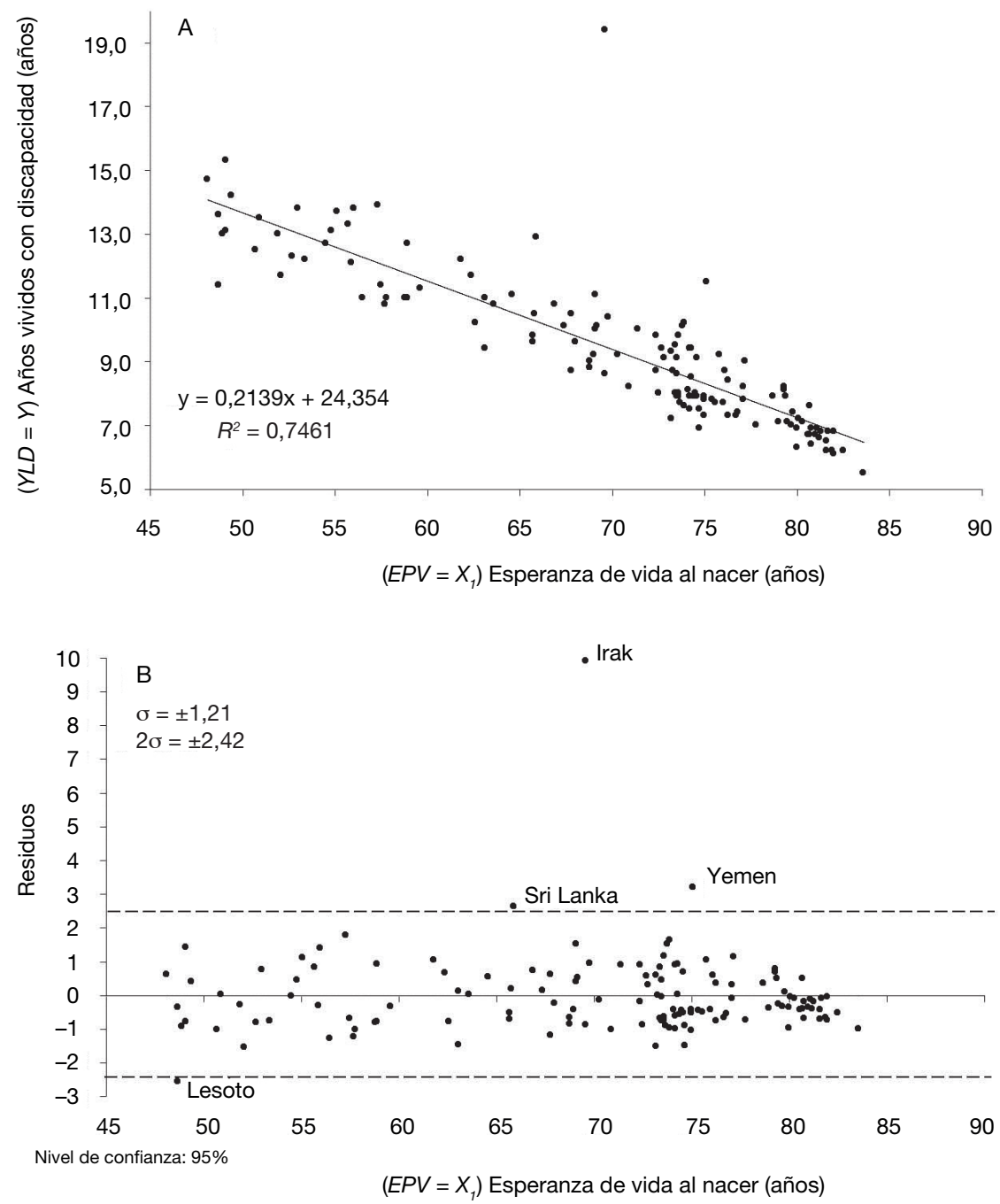

Figura 4. Curva de regresión ajustada entre YLD y EPV (A). Gráfico de residuales de la variable independiente EPV (B).

Fuente: OMS, Informe mundial sobre la discapacidad, 2011. PNUD, Informe sobre el desarrollo humano, 2014. Elaboración propia.

condicionan el coeficiente explicativo de la regresión. Es evidente que se trata de países, especialmente los tres primeros, que, en el último cuarto de siglo, han padecido serios conflictos armados, razón que podría condicionar los registros obtenidos. Por su parte, Lesoto, estado que apenas alcanza los dos millones de 
habitantes, puede resultar un caso interesante para explicar la relación entre los años vividos con discapacidad y la prevalencia de personas contagiadas con el VIH/sida ${ }^{8}$, motivo que puede estar vinculado a los registros anómalos detectados en el modelo (figura 4).

Sin embargo, y con la salvedad de las observaciones identificadas, la distribución geográfica de ambas variables permite observar que, para el conjunto de las poblaciones de los países que cuentan con las expectativas de vida más reducidas, suele coincidir un registro elevado de años vividos con discapacidad. Mientras, en los países cuya población tiende a ser más longeva, los años vividos con discapacidad son menores. No obstante, respecto a estos últimos, conviene introducir un matiz, puesto que hay estudios que señalan que, tanto para países de la Unión Europea (Jagger et al., 2008) como incluso para ciudades como Barcelona (Espelt et al., 2010), la prevalencia de la discapacidad aumenta a partir de los 65 años de edad, y especialmente atendiendo al sexo y al nivel de instrucción, entre otras variables vinculadas a la realización de las actividades básicas de la vida diaria (ABVD).

\subsection{Años vividos con discapacidad e indice de desigualdad de género}

$\mathrm{Al}$ igual que sucede con otros colectivos sociales oprimidos por la etnia, la edad, la orientación sexual o la identidad, las mujeres con discapacidad, dentro de su diversidad, son un colectivo con mayor riesgo de padecer vulnerabilidad social: «Women with disabilities are recognised to be multiply disadvantaged, experiencing stigma due to both gender and disability» (Parnes et al., 2009: 1174). Pese a esta situación, en los últimos años, se observan cada vez mayores avances en materia de visibilidad y reconocimiento social de las mujeres con diversidad funcional. A pesar de ser un grupo que puede verse afectado con más facilidad por mecanismos de exclusión social, ellas cada vez participan de manera más activa en la transformación social de sus comunidades mediante importantes redes de asociacionismo (Arenas, 2013: 90). La relación entre los años vividos con discapacidad y el índice de desigualdad de género ${ }^{9}$ permite, al igual que los anteriores indicadores considerados, realizar otra aproximación a las implicaciones sociales y de desarrollo entre los países, siendo una herramienta útil para realizar una descripción mundial sobre el paralelismo entre las diferentes ratios de ambos indicadores (figura 5).

Dicha relación permite identificar, en este modelo, unas tendencias globales en las que el índice de desigualdad de género puede llegar a explicar el 64,7\%

8. Según las estimaciones del CIA World Factbook para el año 2014, este país registra una prevalencia del virus del VIH/sida del $23,39 \%$ en las personas de entre 15 y 49 años. Al mismo tiempo, se calcula que, en términos absolutos, hay 314.600 personas infectadas con el virus.

9. El IDG es un indicador compuesto realizado por el programa de las Naciones Unidas para el Desarrollo (PNUD). En su elaboración, se considera las tasas de partos entre mujeres adolescentes, las estadísticas de escolarización femenina, la representación parlamentaria de las mujeres y la participación femenina en el mercado laboral formal. 


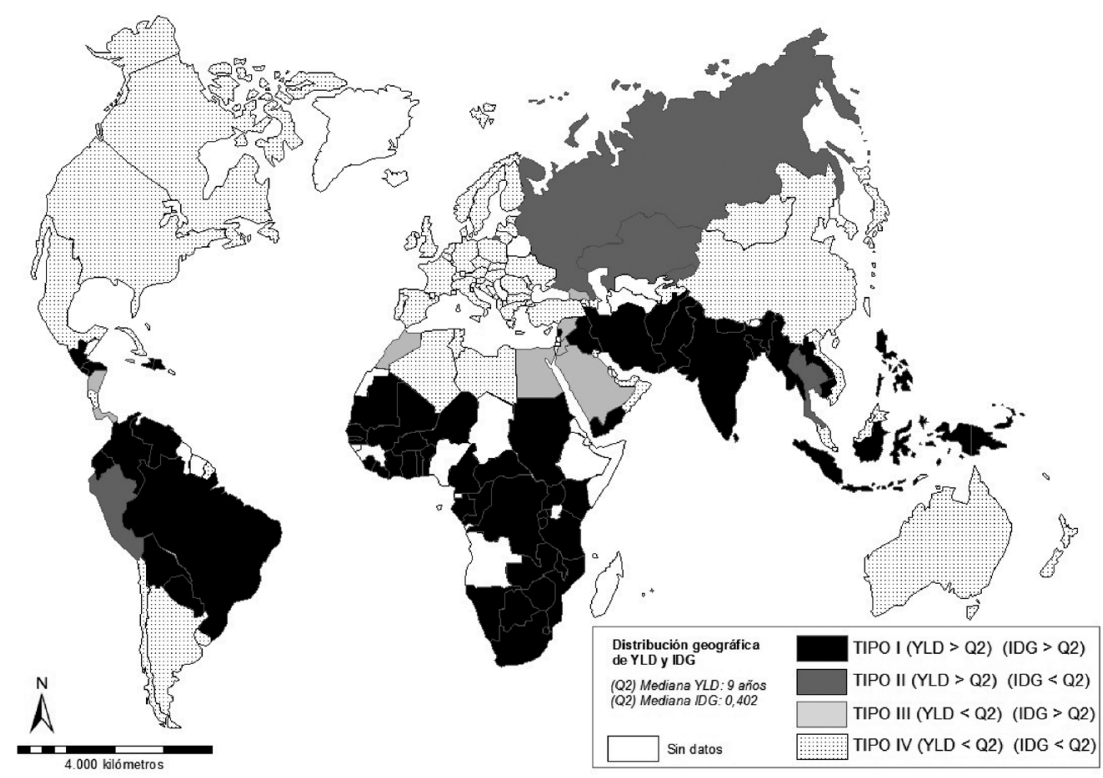

Figura 5. Distribución de los años vividos con discapacidad (YLD) e índice de desigualdad de género (IDG).

Fuente: OMS, Informe mundial sobre la discapacidad, 2011. PNUD, Informe sobre el desarrollo humano, 2014. Elaboración propia.

de los años vividos con discapacidad, porcentaje que se podría incrementar si se excluyera del análisis los outliers detectados, que, en este caso, son siete (figura 6). Representan al 5,18\% de los países incluidos en el modelo de regresión y se sitúan entre Oriente Próximo (Iraq, Egipto, Siria y Arabia Saudí) y África (Ruanda, Botsuana y Burundi). Teniendo en cuenta la diversidad de situaciones que se incluyen bajo el índice de desigualdad de género o las deficiencias muestrales que pudiera haber en esta fuente, entre otras, es muy complejo encontrar explicaciones que vayan más allá de la simple descripción del resultado. Pero es evidente que la desigualdad en general, y la de género en particular, no solo lastra los niveles de desarrollo de las mujeres, sino también del conjunto de la sociedad, tal como resalta la curva de regresión, el gráfico de residuales y el mapa asociado.

Esta distribución geográfica desigual permite reflexionar acerca de la relación entre género y discapacidad, pues existen estudios regionales que se han centrado en los aspectos asociados a determinados tipos de patologías y a los hábitos de vida diferenciales entre mujeres y hombres que inciden en distintas edades en la prevalencia de la minusvalía (Crimmins et al., 2010). Existen también trabajos como Palència et al. (2014) que, atendiendo a las diferentes políticas familiares y de género en la Unión Europea, miden cuantitativamente 

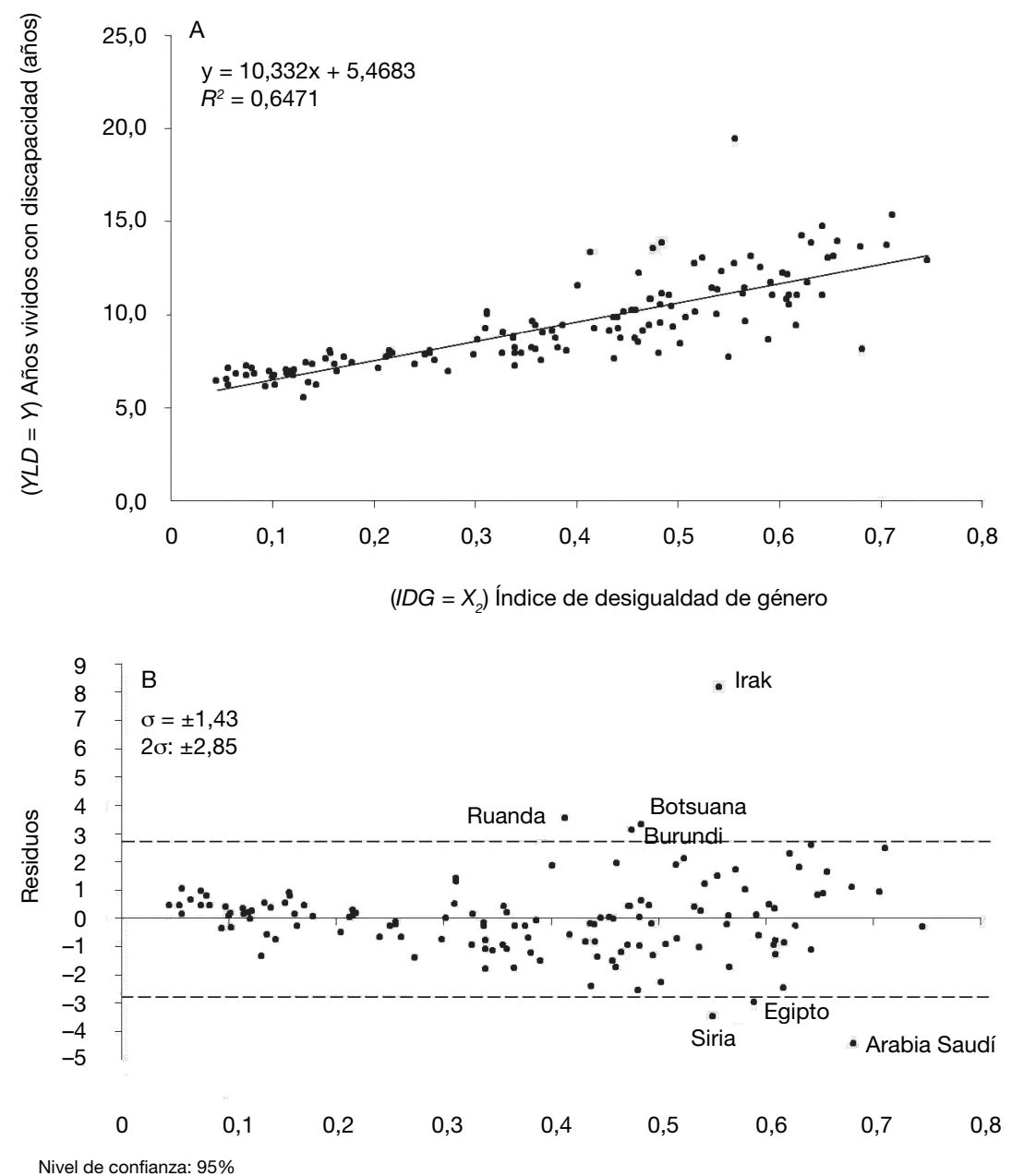

IInf $=x$ ) Índire de decinu ıaldad de nénern

Figura 6. Curva de regresión ajustada entre YLD e IDG (A). Gráfico de residuales de la variable independiente IDG (B).

Fuente: OMS, Informe mundial sobre la discapacidad, 2011. PNUD, Informe sobre el desarrollo humano, 2014. Elaboración propia.

el estado general de salud de las poblaciones. Para ello, consideran variables como el sexo, la edad, el lugar de nacimiento, el nivel de estudios, el estado civil y la relación con la actividad. De hecho, y a diferencia de lo que sucede a escala mundial, si se consideran solo los veinte países más igualitarios, es decir aquellos que cuentan con los índices de desigualdad de género más bajos, ni la 


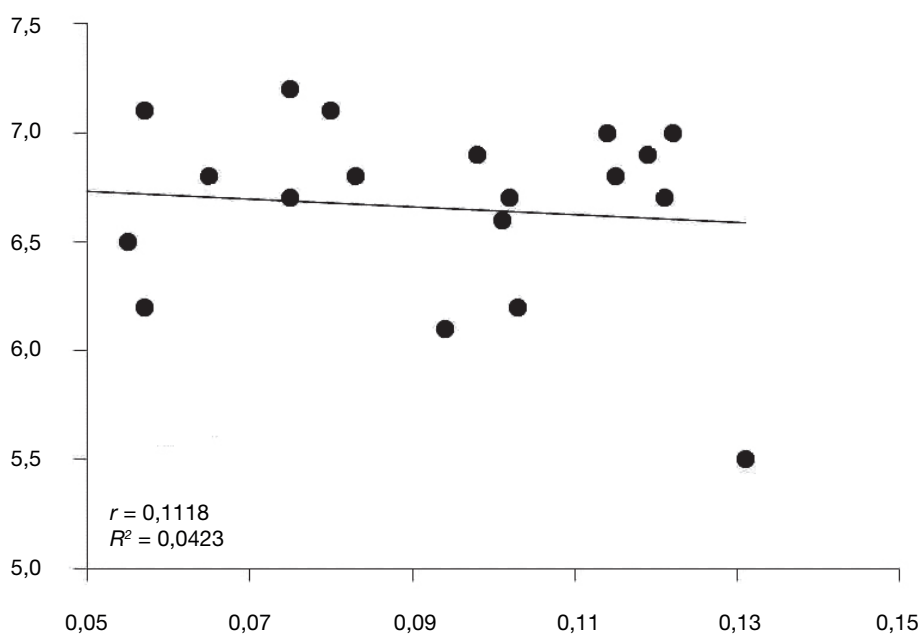

Figura 7. Años vividos con discapacidad e índice de desigualdad de género para los veinte países más igualitarios. Correlación y regresión.

Fuente: OMS, Informe mundial sobre la discapacidad, 2011. PNUD, Informe sobre el desarrollo humano, 2014. Elaboración propia.

correlación de ambas variables ni su regresión permitirían obtener resultados válidos que explicaran los paralelismos que existen entre ambas variables a escala global (figura 7).

De esta manera, la influencia que pueda tener la desigualdad de género sobre la discapacidad, al menos en los países más igualitarios, no pasa tanto por los procesos sociales que mide el índice de desigualdad de género, sino más bien por las diferencias en los modelos de familia, las políticas de género y de salud pública y las estructuras demográficas según edad, sexo, actividad y nivel de instrucción de la población. Este planteamiento se puede comprobar también porque, en el modelo utilizado en este trabajo, los años vividos con discapacidad no aparecen desagregados por sexo, hecho que aporta más argumentos para indagar acerca de la relación de la discapacidad, no solamente con la desigualdad de género, sino también con las diferencias de género.

Pues, en efecto, el Informe mundial sobre la discapacidad (2011:31) refleja, tanto para países de ingresos altos como para países de ingresos bajos, que las tasas de prevalencia de la discapacidad, moderada y grave, no solo son superiores entre las mujeres que entre los hombres, sino que también lo son a distintas edades por sexo, ya sea para jóvenes, adultos o mayores. En ese sentido, se puede comprobar que la distribución geográfica de los años vividos con discapacidad presenta cierto paralelismo con el reparto del índice de desigualdad de género, aunque son las diferencias de género las que mejor pueden llegar a explicar los distintos registros para mujeres y hombres en las tasas de prevalencia de la discapacidad o en los años de vida sana. 


\section{Conclusiones}

En este estudio, junto a una revisión bibliográfica sobre sobre discapacidad y pautas de desarrollo humano a distintas escalas, se ha utilizado una serie de datos y estimaciones para describir y evaluar la relación que mantiene la discapacidad con una selección de indicadores sociales y de desarrollo. Se ha empleado un método de análisis cuantitativo basado en una correlación lineal para medir de modo independiente el grado de asociación entre las variables inicialmente seleccionadas.

Dicho procedimiento ha servido para plantear un análisis de regresión múltiple, tomando como variable endógena $(y)$ las pautas de distribución geográfica de los años vividos con discapacidad (YLD) y así poder explicar su comportamiento. Para ello, se utilizaron como variables explicativas $\left(x_{i}\right)$ aquellas con las que, por un lado, se construye el índice de desarrollo humano, pero de manera desagregada: esperanza de vida al nacer (EPV), promedio de años de escolaridad (MYS) y renta per cápita (RTA), y, por otro lado, el índice de desigualdad de género (IDG) y la tasa de población urbana (URB).

De esta manera, tan solo dos variables - esperanza de vida al nacer (EPV) e índice de desigualdad de género (IDG) — han mostrado un ajuste más fiable al presentar el $R^{2}$ más elevado: 0,7867, y predicen el mayor porcentaje de la ecuación obtenida $\left(y=18,2477-0,1498 x_{1}+4,2387 x_{2}\right)$ por el método de mínimos cuadrados, que, en nuestro caso, ha excluido la distribución de la renta per cápita, el promedio de años de escolaridad y la proporción de población urbana. Sin embargo, la extrapolación empírica de estos resultados plantea ciertos interrogantes en términos de causalidad. No en vano, y como apuntan otros estudios, la multicausalidad de la discapacidad es uno de los rasgos que mejor la define. Es decir, se necesita incorporar otras variables que consideren las pautas culturales, de comportamiento y asistenciales a una escala mucho más detallada que la mera abstracción del fenómeno a grandes conjuntos de países y que, además de describir las causas de la discapacidad, contribuyan a explicarla.

Pese a las limitaciones que ofrecen las fuentes de información, las puntuaciones de los valores obtenidos confirman la idea que vincula el desarrollo de las poblaciones, no tanto con la prevalencia de la discapacidad, sino con los años vividos con ella, ya que hay países cuya prevalencia es elevada (normalmente, los más desarrollados) y, al mismo tiempo, con pocos años vividos con discapacidad. En cambio, en una parte significativa de los denominados "países del mundo mayoritario», con una esperanza de vida más baja al nacer, existen en su conjunto bastantes años vividos con discapacidad con, aparentemente, una baja prevalencia de aquella.

Conviene remarcar la relación que mantienen los años vividos con discapacidad y el índice de desigualdad de género, pues esta última variable añade más fiabilidad a la ecuación obtenida. Se ha podido confirmar que esa relación, que se constata al tener en cuenta todos los países, desaparece cuando solo se considera a los estados más igualitarios. Hecho que, en principio, viene a corroborar que la prevalencia de la discapacidad en dichos países no se ve condicionada por los procesos sociales que reflejan los indicadores con los que se construye el índice de 
desigualdad de género, y sí por otros indicadores asociados a las diferencias en las estructuras sociodemográficas de la población, las políticas sociales o los distintos tipos de familia y composición de los hogares que algunas autoras han demostrado.

Por último, cabe destacar que, con la utilización y la interpretación de los datos disponibles, se han podido establecer unas tendencias generales acerca de la relación cuantitativa entre desarrollo regional y discapacidad. Ello se ha realizado mediante la formulación de una ecuación que describe la distribución geográfica de los años vividos con discapacidad, pero que no es suficiente para afirmar un principio de causalidad que vaya más allá de los datos muestrales y sea capaz de articular una teoría lo suficientemente válida como para que involucre a las variables que miden el desarrollo humano de las poblaciones, pues somos conscientes que una aproximación más integral al fenómeno desde la geografía social y del bienestar requiere también del empleo de procedimientos de análisis de corte cualitativo y de un enfoque de carácter más local y centrado en alguna de las funciones básicas de las personas.

\section{Referencias bibliográficas}

Abberley, Paul (1987). «The concept of oppression social and the development of a social theory of disability». Disability, Handicap \& Society [en línea], 2 (1), 5-19. $<$ http://dx.doi.org/10.1080/02674648766780021>

Arenas Conejo, Míriam (2013). «Disabled women and transnational feminism: Shifting, boundaries and frontiers». En: Moore, Michelle (ed.). Moving beyond boundaries in disability studies: Rights, spaces and innovations. Oxford: Routledge, 90-102.

BARnes, Colin (2010). «Discapacidad, política y pobreza en el contexto del "Mundo Mayoritario"». Política y Sociedad, 47 (1), 11-25.

Barnes, Colin y Mercer, Geof (2010). Exploring disability. Cambridge: Polity Press.

BARnes, Colin y SHeldon, Alison (2010). «Disability, politics and poverty in a majority world context». Disability \& Society [en línea], 25 (7), 771-782. $<$ http://dx.doi.org/10.1080/09687599.2010.520889>

Cambois, Emmanuelle; Clavel, Aurore; Romieu, Isabelle y Robine, Jean-Marie (2008). «Trends in disability-free life expectancy at age 65 in France: Consistent and diverging patterns according to the underlying disability measure». European Journal of Ageing [en línea], 5 (4), 287-298. $<$ http://dx.doi.org/10.1007/s10433-008-0097-1>

Chouinard, Vera; Hall, Edward y Wilton, Robert (2010). «Introduction: Towards enabling geographies». En: Chouinard, Vera; Hall, Edward y Wilton, Robert (ed.). Towards enabling geographies: "Disabled» bodies and minds in society and space. Surrey: Ashgate, 1-21.

Coleridge, Peter (1993). Disability, liberation and development. Oxford: Oxfam.

Crimmins, Eileen M.; Kim, Jung K. y Solé-Auró, Aïda (2010). «Gender differences in health: Results from SHARE, ELSA and HRS». The European Journal of Public Health [en línea], 1-11. $<$ http://dx.doi.org/10.1093/eurpub/ckq022>

Dorn, Michael L. y Kerrns, Carla C. (2010). «Disability, Health and Citizenship». En: Smith, Susan J.; Pain, Rachel; Marston, Sallie A. y Jones III, John Paul (ed.). The SAGE Handbook of Social Geographies. Londres: SAGE Publications, 99-117. 
Dyck, Isabel (2011). «Embodied life». En: Del Casino Jr., Vicent J.; Thomas, Mary E.; Cloke, Paul y Panelli, Ruth (ed.). A companion to social geography. Sussex: Wiley-Blackwell, 346-361.

Eide, Arne H. e Ingstad, Benedicte (2011). Disability and poverty: A global challenge. Bristol: Polity Press.

Espelt, Albert; Font-Ribera, Laia; Rodríguez-Sanz, Maica; Artazcoz, Lucía; Ferrando, Josep; Plaza, Aina; Borrell, Carme (2010). «Disability among older people in a southern European city in 2006: Trends in gender and socioeconomic inequalities». Journal of Women's Health [en línea], 19 (5), 927-933. <http://dx.doi.org/10.1089/jwh.2009.1608>

Estivill, Jordi (2003). Panorama de la lucha contra la exclusión social: Conceptos y estrategias. Ginebra: Oficina Internacional del Trabajo.

GleEson, Brendan (1999). Geographies of disability. Londres: Routledge.

Grech, Shaun (2014). "The spaces of poverty: Renegotiating place and disability in the global south». En: Soldatic, Karen; Morgan, Hannah y Roulstone, Alan (ed.). Disability, spaces and places of policy exclusion. Oxford: Routledge, 48-63.

Gregory, Derek; Johnston, Ron; Pratt, Geraldine; Watts, Michael J. y Whatmore, Sarah (ed.) (1981). The dictionary of human geography. Sussex: Wiley-Blackwell, 2009.

Groce, Nora; Kembhavi, Gayatri; Wirz, Sheila; Lang, Raymond; Trani, JeanFrançois; Kett, Maria (2011). Poverty and Disability: A critical review of the literature in low and middle-income countries. Londres: Leonard Cheshire Disability and Inclusive Development Centre.

Imrie, Rob (1996). Disability and the city. Londres: Paul Chapman Publishing.

Jagger, Carol; Gilles, Clare; Moscone, Francesco; Cambois, Emmanuelle; Van Oye, Herman; Nusselder, Wilma y Robine, Jean-Marie (2008). «Inequalities in healthy life years in the 25 countries of the European Union in 2005: A crossnational meta-regression analysis». The Lancet [en línea], 372 (9656), 2124-2131. <http://dx.doi.org/10.1016/S0140-6736(08)61594-9>

Keyes, Corey Lee (1998). "Social Well-Being». Social Psychology Quaterly, 61 (2), 121-140.

Kitchin, Rob (2000). Disability, space and society. Sheffield: Geographical Association.

- (1998): "“Out of Place", "Knowing One’s Place": Space, power and the exclusion of disabled people». Disability \& Society [en línea], 3 (3), 343-356. <http://dx.doi.org/10.1080/09687599826678>

Knox, Paul y Pinch, Steven (1982). Urban social geography: An introduction. Essex: Pearson, 2000.

Lynch, Scott M.; Brown, J. Scott y Taylor, Miles G. (2009). «Demography of disability». En: Uhlenberg, Peter (ed.). International Handbook of Population Aging. Texas: Springer, 567-582.

McEwan, Cheryl y Butler, Ruth (2007). «Disability and development: Different models, different places». Geography Compass [en línea], 1 (3), 448-466. <http://dx.doi.org/10.1111/j.1749-8198.2007.00023.x>

Mitra, Sophie (2006). "The capability approach and disability». Journal of Disability Policy Studies [en línea], 16 (4), 236-247. <http://dx.doi.org/10.1177/10442073060160040501>

Mitra, Sophie; Posarac, Aleksandra y Vick, Brandon (2013). «Disability and poverty in developing countries: A multidimensional study». World Development [en línea], $41,1-18$. <http://dx.doi.org/10.1016/j.worlddev.2012.05.024> 
Montgomery, Mark R.; Hewett, Paul C. (2005). "Urban poverty and health in developing countries: Household and neighborhood effects». Demography [en línea], 42 (3), 397-425. <http://dx.doi.org/10.1353/dem.2005.0020>

Naciones Unidas (1990). Compendio de datos estadísticos sobre los impedidos. Nueva York: Departamento de Asuntos Económicos y Sociales Internacionales.

Olivera, A. (2006). "Geografía y discapacidad». En: Nogué, Joan y Romero, Joan (ed.). Las otras geografías. Valencia: Tirant lo Blanch, 527-542.

Organización Mundial de la Salud (2011). Informe mundial sobre la discapacidad. Ginebra: Ediciones de la OMS.

Organización Panamericana de la Salud (2012). Aplicación de la Clasificación Internacional del Funcionamiento de la Discapacidad y de la Salud en estudios de prevalencia de discapacidad en las Américas. Washington: OPS.

Palència, Laia; Malmusi, Davide, De Moortel, Deborah; Artazcoz, Lucía; BacKhans, Mona; Vanroelen, Christophe y Borrell, Carme (2014). «The influence of gender equality policies on gender inequalities in health in Europe». Social Science \& Medicine [en línea], 117, 25-33. <http://dx.doi.org/10.1016/j.socscimed.2014.07.018>

Palmer, Michael (2011). "Disability and poverty: A conceptual review». Journal of Disability Policy Studies [en línea], 21 (4), 210-218. <http://dx.doi.org/10.1177/1044207310389333>

Parnes, Penny; Cameron, Debra; Christie, Nancy; Cockburn, Lynn; Hashemi, Goli y Yoshida, Karen (2009). "Disability in low-income countries: Issues and implications». Disability and Rehabilitation [en línea], 31 (14), 1170-1180. <http://dx.doi.org/10.1080/09638280902773778>

Puga González, María Dolores y Abellán García, Antonio (2004). El proceso de discapacidad: Un análisis de la encuesta sobre discapacidades, deficiencias y estado de salud. Alcobendas (Madrid): Fundación Pfizer.

Robine, Jean-Marie; Bucquet, Denis y Ritchie, Karen (1991). «L'espérance de vie sans incapacité, un indicateur de l'evolution des conditions de santé au cours du temps: Vingt ans de calcul». Cahiers québecóis de démographie [en línea], 20 (2), 205-235. <http://id.erudit.org/iderudit/010084ar>.

Rodríguez Cabrero, Gregorio (2011). «Políticas sociales de atención a la dependencia en los regímenes de bienestar de la Unión Europea». Cuadernos de Relaciones Laborales, 29 (1), 13-42.

Rojo-Pérez, Fermina; Fernández-Mayoralas, Gloria y Rodríguez-Rodríguez, Vicente (2015). «Global perspective on quality in later life». En: GLATZER, Wolfgang; Camfield, Laura; Møller, Valerie y Rojas, Mariano (ed.). Global handbook of quality of life: Exploration of well-being of nations and continents. Londres: Springer, 469-490.

Salomon, Joshua A.; Wang, Haidong; Freeman, Michael K.; Vos, Theo; Flaxman, Abraham D.; Lopez, Alan D. y Murray, Christopher J. (2013). «Healthy life expectancy for 187 countries, 1990-2010: A systematic analysis for the Global Burden Disease Study 2010». The Lancet [en línea], 380 (9859), 2144-2162. <http://dx.doi.org/10.1016/S0140-6736(12)61690-0>

Thomas, Carol (2007). Sociologies of Disability and Illness. Nueva York: Palgrave Macmillan. 